\title{
Lowland islands at the water-land nexus in Lixiahe, China: A boundary approach
}

\author{
Dongxue Lei \\ School of Architecture and Urban Planning, Nanjing University, China \\ dxlei@smail.nju.edu.cn
}

\begin{abstract}
Historically known as China's 'Netherlands', the lowlands of Lixiahe were and still are characterized by vast waterscapes. This paper introduces an island society fostered by this wet landscape, which thrived in premodern times and has undergone a transition into modernity. From a long-term perspective, there have been constant interactions between this island society and the water-land environments. This study details such socio-natural interactions and reconsiders the role of natural settings in the evolution of this island society in the modern context of intensifying human interventions. A comparative study is conducted in two periods of premodern and modern times, and a parallel examination is conducted into three levels of this island society to explore island relations. A boundary approach based on landscape ecology theories is employed to interpret the complex socio-natural interactions in both temporal and spatial dimensions. Through this historical exploration, the paper concludes with three links between resilience thinking and architecture/planning practice in wet landscapes and discusses contemporary issues connected with the socio-ecological resilience of these lowland islands.
\end{abstract}

Keywords: boundary approach, built artifacts, China, water-land nexus, Lixiahe, lowland islands https://doi.org/10.24043/isj.158 • Received May 2020, accepted March 2021

(C) Island Studies Journal, 2021

\section{Introduction}

In island studies, the research objects, often considered in relation to the mainland, are generally built environments surrounded by pure waterscapes, such as island settlements, towns, and cities in rivers, lakes, estuaries, and oceans (Grydehøj et al, 2015; Grydehøj, 2015). Limited attention has been paid to wet landscapes between the terrestrial and aquatic realms, such as flood plains and wetlands. However, mixed water and land environments, or inbetween/hybrid environments (Krause, 2017; Lahiri-Dutt, 2014a) can become a nursery ground for island settlements within a specific socio-natural context. From hydromorphic and geomorphic perspectives, flood plains are low-lying landscapes that are periodically subject to inundation by various sources of water (Tockner \& Stanford, 2002). This suggests that the suddenly changed water/land ratio of flood plains can lead to a phenomenon of temporal islandness. Therefore, settlements located in riverine flood plains worldwide, in both urban and rural contexts, may appear as ephemeral islands during severe flooding. Such cases are 
particularly common in Asia's densely populated mega-river basins. For example, cities located within the large flood plains of China's Yangtze, Yellow, and Huai Rivers are at the risk of flooding in heavy rainy seasons, while villages within floodwater retention areas are the most flood-prone locales. Another example is 'chars', a type of river island inhabited by marginalized communities, which seasonally appears in the deltaic flood plains of Bengal (Lahiri-Dutt, 2014b; Lafaye de Micheaux et al, 2018).

Wetlands are also low-lying landscapes that are perennially or periodically saturated with water (Mitsch \& Gosselink, 2011) and, in some cases, included in a broad flood plain (Tockner \& Stanford, 2002). Although wetlands are challenging environments to live with, they provide human development with diverse values (Mitsch \& Gosselink, 2000). Not only do wetlands serve as homes for premodern and contemporary rural inhabitants (Pinke et al, 2016; Krause, 2017; Robertson \& McGee, 2003; Ambastha et al, 2007), but they are also the origin of modern island cities such as Paris and Mexico City (Giblett, 2016; Mitsch \& Gosselink, 2011). As Griblett (2016) observes, natural disasters can take a former wetland city back to its "wetland beginning." Therefore, some former wetland cities that cannot be categorized into typical types of island cities may inherit islandness (e.g. Berlin). Some inland and coastal cities of Asia can also be recognized as island cities as their modern development remains in the background of a wide range of wetland legacies (Dar et al, 2020; Ummai et al, 2011; Guan, 2021). Other than being transformed into urban/rural dwellings, flood plains and wetlands can be converted into artificial waterscapes, such as rice paddies and aquaculture ponds. Settlements situated in artificial waterscapes can thus also be perceived as islands.

The present study introduces a group of island settlements from the lowlands of Lixiahe (里下河), China, which were built in natural waterscapes hundreds of years ago and are now still developing in artificial waterscapes (Figure 1, left). The phenomenon of dwelling on islands in this wet landscape needs to be understood in terms of natural as well as social aspects. By virtue of an average terrain of less than two meters above sea level, these lowlands have been endowed with a wet landscape since ancient times. In the past, this area was a lagoon, which formed around the $5^{\text {th }}$ Century BC. As the coastline continually moved eastward, and the former Yellow River transported large amounts of sediment into the area in the $16^{\text {th }}$ Century AD (Ye, 1986), the lagoon eventually transformed into mixed waterscapes of shallow lakes, wetlands and rivers. Ancient inhabitants succeeded in settling down by building islands in the mixed waterscapes. According to archaeological evidence and gazetteer records, the first population boom in this lowlands was seen during the Eastern Han dynasty (25-220 AD), and a stable island society occasioned by forced immigration emerged in the Ming dynasty (1368-1644). Another island or archipelagic society emerging in an equally wet landscape can be found around Lake Tai on the south Yangtze River deltaic plain. 

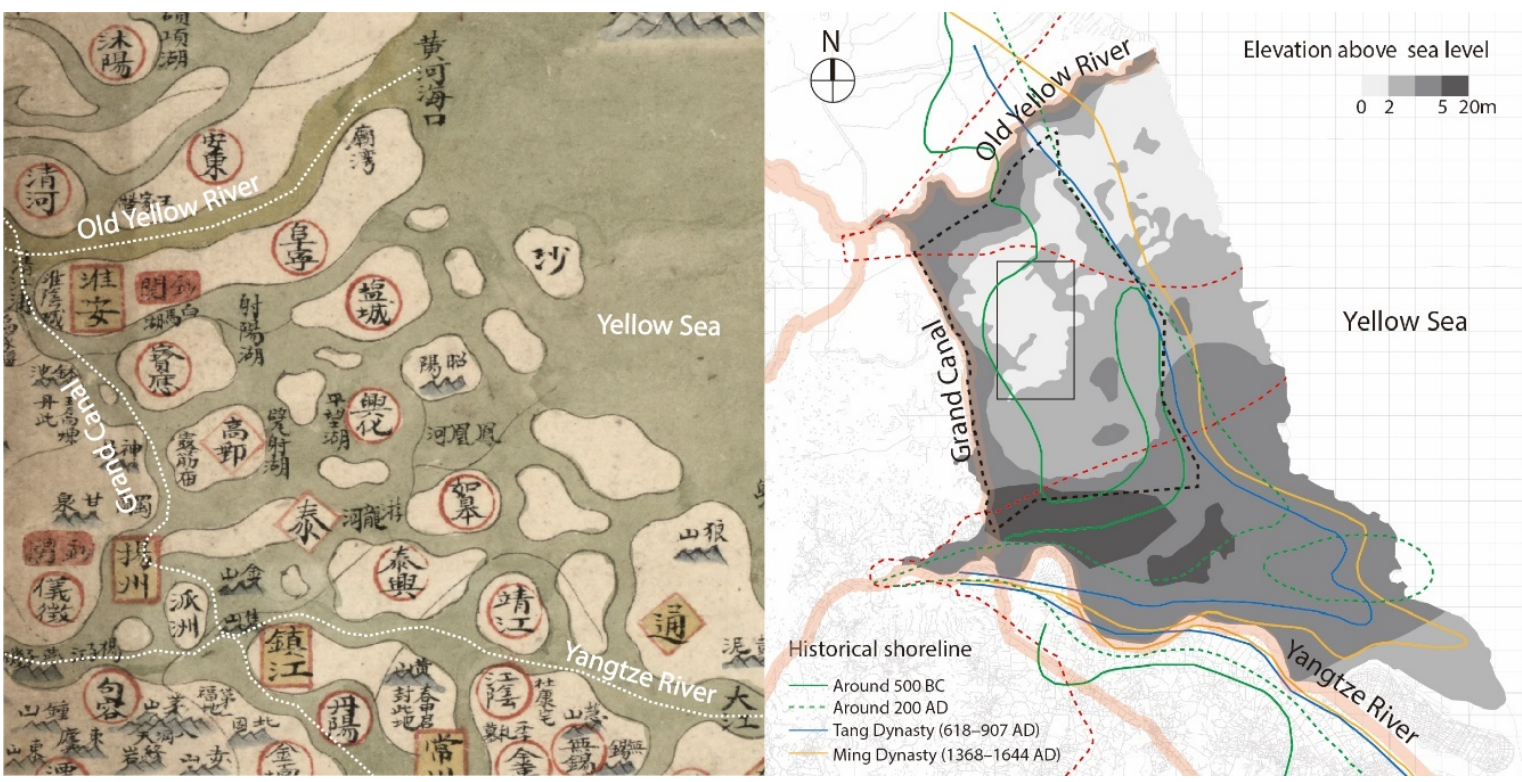

Figure 1. Left: A cognitive map of island settlements in the Lixiahe region around the mid$18^{\text {th }}$ Century. Right: Map of the Lixiahe region and study area. The area with red dashed lines represents the geographical domains of the abandoned Yellow River delta (Ye, 1986; Ha et al, 2005) and Yangtze River delta (Chen, 198). The black dashed lines mark the official borders of Lixiahe. The study area is shown by the black rectangle.

Yet dwelling on islands was not easy in premodern times because the water-land nexus of this wet landscape was extremely unstable. Frequent disasters occurred in the lowlands due to the Lixiahe region's unique topography. Under the dual effects of geological transitions and sea-level changes, Lixiahe was developed from the old delta lands of the Yangtze and Yellow Rivers. Eventually, this plain evolved with a bowl-shaped landform, and the lowlands are situated at its bottom (Figure 1, right). Besides the permanent bodies of water in the lowlands, there are other sources of water input. Water disasters, including floods and waterlogging caused by monsoon rains and typhoon rains, hit the lowlands frequently between the $14^{\text {th }}$ and $19^{\text {th }}$ Centuries (Zhang, Chen, \& Gu, 2016). Floodwaters from the Grand Canal, the Old Yellow River (Huai River), and the Yangtze River frequently flowed into the lowlands before the $20^{\text {th }}$ Century $(\mathrm{Xu}, 1995)$.

This wet landscape is also prone to problems associated with dry conditions. During the dry season, the area receives less water than is required by agricultural irrigation systems, bearing in mind the rapid rate of evaporation from the broad expanses of surface water. According to local records, extreme water disasters and droughts occurred around once every two years between 1853-1949. In the face of the dynamic wet conditions, islanders built artifacts that functionally and symbolically negotiate with this instability: for example, constructing islands adjacent to other islands and connecting them by bridges, utilizing embankments and walls to intervene in the water-land nexus, and setting up temples to pray for safety.

To create more stable water-land environments, human interventions within Lixiahe have been greatly intensified in modern times. Due to the implementation of numerous water conservancy projects (Liu et al, 2013), including the building of drainage systems, pumping stations, and polders (Xu, 1995), the frequency of extreme flooding and droughts in the lowlands decreased to once every five years between 1949-2000 (兴化市防汛防旱指挥部办公室, 
2001). At the same time, the wet landscape of the lowlands has been thoroughly reshaped. For a long time, the lowlands' wet conditions have been regarded as a negative factor in social life and economic activities, and the wet landscape has been considered a wasteland. Therefore, under the driving force of the national-led agricultural modernization and subsequent rural urbanization, natural waterscapes experienced massive land reclamation and were converted into ground-bases for diverse built artifacts (buildings, aquacultural ponds, etc.). In this enduring dry development, the natural wetness of the lowlands has been reduced to a minimum.

Human intervention in dynamic water-land environments is a permanent theme in this wet landscape. Such interventions are realized through building behavior and then embodied by built artifacts (McGrath \& Lei, 2021). Using fieldwork, gazetteers, historical maps, and multi-disciplinary research, we can find records of various built behaviors and artifacts in the evolution of these lowland islands. The present paper presents socio-natural interactions in the lowlands in both premodern and modern times and analyses their consequences. Based on a long-term perspective, this study further investigates the degree to which the natural settings of the lowlands affect social dynamics in modern times. The two study periods are defined according to the history of rural China. The beginning of premodern history in Lixiahe goes back to the $16^{\text {th }}$ Century, when a large group of island settlements began to thrive materially, eventually achieving a stable morphology that lasted for centuries. Up until the 1950s, the lowlands retained most of their natural waterscapes. The period from the 1950s up to the most recent (2010-2019) is defined as the modern period, during which both natural and social environments have undergone tremendous changes, with the drying out of the lowlands.

The present study's broad geographical scope allows it to contribute to explorations of island relations and archipelagic thinking in island studies (Stratford et al, 2011; Pugh, 2013, 2018; Stratford, 2013). Observations of this island society are synchronically conducted at three levels: individual island, island corridor, and archipelago. These three levels are not independent; understanding the consequences of socio-natural interactions at one level is necessary for understanding those at the other two levels. It should be noted that the starting and ending times of the two periods differ between levels because the specific socio-natural interactions at the three levels were of different durations.

\section{A boundary approach}

Because we will explore socio-natural interactions, the natural and built environments must be considered as whole on every level. Inspired by the boundary framework from landscape ecology (Cadenasso \& Pickett, 2003), this study focuses on the boundaries of one or more islands on the landscape scale to reveal complex socio-natural interactions. The boundary framework is applicable in this study because it has been devised as an interdisciplinary approach to understanding the inclusion of humans and the organization of their built artifacts within an ecosystem (McGrath et al, 2007). This approach is, moreover, applicable to researching objects at any spatial scale and places emphasis on the temporal as well as spatial dimensions of a research context.

In landscape ecology, "landscapes consist of two kinds of structures-patches and boundaries" (Cadenasso et al, 2003, p. 751). Patches are "volumes that can be distinguished compositionally, structurally, or functionally from adjacent volume at a given scale" (Cadenasso et al, 2003, p. 751), representing spatial heterogeneity that can exist in "bodies of 
water, volumes of soil, and land-water transitions" (Cadenasso et al, 2003, p. 750). Boundaries are structural and functional entities between patches, through which patches interact in the flows (Cadenasso \& Pickett, 2007). Based on this interpretation, the water-land environments, including islands, can be viewed as an assemblage of different types of heterogeneous patches, and boundaries can be defined as a water-land interface that structurally and functionally supports the existence of one or more islands.

The boundary framework is viewed as an observational tool in this study. First, it provides two hints to assist in analyzing boundary structure and function (Cadenasso \& Pickett, 2007). Boundaries are three-dimensional and composed of architectural, compositional, symbolic, or perceptual features, and can be wide or narrow, sharp or subtle. Moreover, boundary function can be disturbed by boundary structure as boundaries serve as a medium facilitating exchange of materials, energy, organisms, or information between patches. Therefore, analysis of the structure of the water-land interface should include artificial as well as natural elements, and the function of the water-land interface can be revealed by analyzing the motivation of built behavior in intervening at the water-land nexus.

Apart from supporting the textual interpretations of boundary structure and function, the boundary framework expands its applied field to morphological analysis and argues that the existence of boundaries can be visualized by patch contrast. To represent the water-land interface in a wet landscape, patch classification needs to move away from the water-land dichotomy, which originates from the nature-culture binary in multiple disciplines (Krause, 2017; Lahiri-Dutt, 2014a; Hayward, 2012; Stratford et al, 2011). For example, a patch of rice paddies or aquaculture ponds can be considered aquatic or terrestrial depending on the specific research context. Therefore, it is essential to first recognize that there is a gradient between water and land in a wet landscape and thus that water-land environments need to be subdivided as in Table 1 below.

Table 1. Patch classification in the context of wet landscape.

\begin{tabular}{|l|l|l|l|}
\hline Class 1 & Water & Water-Land & Land \\
\hline Class 2 & Lake/ & $\begin{array}{l}\text { Reed marsh/ } \\
\text { River } \\
\text { Waterlogged paddy field/ } \\
\text { Aqdy field with embankments/ } \\
\text { Aquaculture pond }\end{array}$ & $\begin{array}{l}\text { Unpopulated land/ } \\
\text { Raised field/ } \\
\text { Populated land }\end{array}$ \\
\hline
\end{tabular}

As ecologists have suggested, the function of even the same patches varies in accordance with spatial level (Cadenasso \& Pickett, 2007). This means that the above types of patches in Class 2 need to be regrouped in accordance with the research context of each level. Here, the intensity of human interventions is employed to devise a new classification (see Table 2 below). A certain type of patch may be removed on one level as it has little relationship to the research question. For example, the 'river' patch is ignored on Level 3 as it does not contribute to the phenomenon of boundaries of an archipelago. On each level, two periods share the same classification rule to illustrate and compare the impact of human interventions on the morphological transformation of the lowland islands. 
Table 2. Patch classification on each level.

\begin{tabular}{|l|l|l|l|l|l|}
\hline \multicolumn{2}{|c|}{ Level 1 } & \multicolumn{2}{c|}{ Level 2 } & \multicolumn{2}{c|}{ Level 3 } \\
\hline Class 1 & Class 2 & Class 1 & Class 2 & Class 1 & Class 2 \\
\hline Water & $\begin{array}{l}\text { Lake/River/Reed } \\
\text { marsh }\end{array}$ & Water & Lake/River & Water & Lake/Reed marsh \\
\hline $\begin{array}{l}\text { Unpopulated } \\
\text { land }\end{array}$ & Unpopulated land & Reed marsh & Reed marsh & $\begin{array}{l}\text { Agricultural land } \\
\text { with natural } \\
\text { boundaries }\end{array}$ & $\begin{array}{l}\text { Waterlogged } \\
\text { paddy field/ } \\
\text { Raised field }\end{array}$ \\
\hline $\begin{array}{l}\text { Agricultural } \\
\text { land }\end{array}$ & $\begin{array}{l}\text { Waterlogged } \\
\text { paddy field/ } \\
\text { Paddy field with } \\
\text { embankments/ } \\
\text { Raised field/ } \\
\text { Aquaculture pond }\end{array}$ & $\begin{array}{l}\text { Aquaculture } \\
\text { pond }\end{array}$ & Aquaculture pond & $\begin{array}{l}\text { Agricultural land } \\
\text { with built } \\
\text { boundaries }\end{array}$ & $\begin{array}{l}\text { Paddy field with } \\
\text { embankments/ } \\
\text { Aquaculture pond }\end{array}$ \\
\hline $\begin{array}{l}\text { Populated } \\
\text { land }\end{array}$ & $\begin{array}{l}\text { Populated land } \\
\text { Cropland }\end{array}$ & $\begin{array}{l}\text { Waterlogged } \\
\text { paddy field/ } \\
\text { Paddy field with } \\
\text { embankment/ } \\
\text { Raised field/ }\end{array}$ & $\begin{array}{l}\text { Populated } \\
\text { land }\end{array}$ & $\begin{array}{l}\text { Populated } \\
\text { land }\end{array}$ \\
\hline
\end{tabular}

\section{Level 1: Individual island}

The strategy of constructing islands in the lowlands is operationally easy and sustainable. Early inhabitants raised elevated lands in the water by stacking mud and ultimately expanded these islands as their community grew. Surrounding the populated islands, vacant elevated lands were reclaimed as raised fields to cultivate vegetable crops, which is comparable to the ancient farming patterns of the Chinampas in the Valley of Mexico. Swamps with natural lower landforms are more commonly transformed into waterlogged paddy fields (Yuan \& Wang, 2019). Inhabitants traveled among islands by boat in their daily lives.

In this section, the analysis of boundary structure and function is first given to four island settlements in premodern times (Figure 2, left). In the case of Cuiduo (崔垛), besides the boundary that is marked by water and land, island boundaries can be reflected in the edge space of the road system. Meanwhile, several temples with cultural symbolism are located at the periphery of the island. The second case, Zhongbao (中堡), further exemplifies the built behavior when the territory of the island community expands to two pieces of land. Bridges are built at regular intervals to connect two single islands. Temples also appear along the periphery of this island settlement. These two cases suggest that the boundary structure of an island settlement includes water and temples. The existence of boundaries is highlighted by the locational information of temples, and the function of the water boundary in separating an island community can be weakened by bridges.

Shagou (沙沟) is a more detailed case for examining the above inference. With a recorded history of around 2000 years, Shagou is probably among the earliest island settlements in the lowlands. It was built by the first generation of immigrants during the Warring States period (475-221 BC). Unlike Cuiduo and Zhongbao, the territories of which 
are contained within one or two islands, the built-up area of Shagou expanded from one island to five islands, according to oral history. By examining the spatial-temporal information of bridges and temples, it is possible to reveal the morphological development of this island settlement. It can be verified that there are always newly built temples and bridges when this community develops from the east to the west. The widespread distribution of bridges ensures high accessibility to each populated land, and thus the water boundary has limited effect on mobility within this community. The continuous behavior of building temples underlines the need to extend a sense of place and construct new boundary structures amidst the development of this island community.

These three cases illuminate how inhabitants adopt an island model to remain on land and out of the water, while Xinghua (兴化) presents how an island community may proactively engage with the unstable and wet conditions of the lowlands by intervening in the boundary structure. This idea is realized by the building of a wall. In common with other city walls in China's imperial dynasties (Chang, 1970), Xinghua's wall was initially set up for military defense and flood control. In addition, the wall was partially erected between water and land and therefore created a shallow pond within the walled community. The pond not only served as a temporal water source in dry seasons but also as a water storage area during floods. Over time, this kind of boundary structure can influence the original water-land boundaries because sediments easily accumulate near the outer wall. As new pieces of land appeared, the territory of this island community continued to grow beyond the wall. This can be verified by the densely built bridges and regularly distributed temples outside the wall.

By the 1950s, bodies of water surrounding and within these island settlements experienced recession and pollution, and their boundary functions drastically decreased. To cope with the environmental problems that occurred in this wet landscape, a series of infrastructural projects were carried out to promote a dry form of development. Rivers within island settlements were filled and converted to roads, and both walls and bridges were torn down to develop road systems. Swamps were gradually converted into various kinds of agricultural lands, and temples associated with the water-oriented culture were demolished. This dry development accelerated due to the development of small-scale enterprises driven by China's 1978 rural economic reforms (Jin, 1988). Since the 1980s, the environmental conditions of the four island settlements have transformed from a wet scenario to a dry scenario. In the modern period, the boundaries composed of artificial waterscapes may appear to isolate the islands, but their function is largely visual, given that roads and bridges have become the functional medium through which island settlements connect with their outside world (Figure 2, right). 


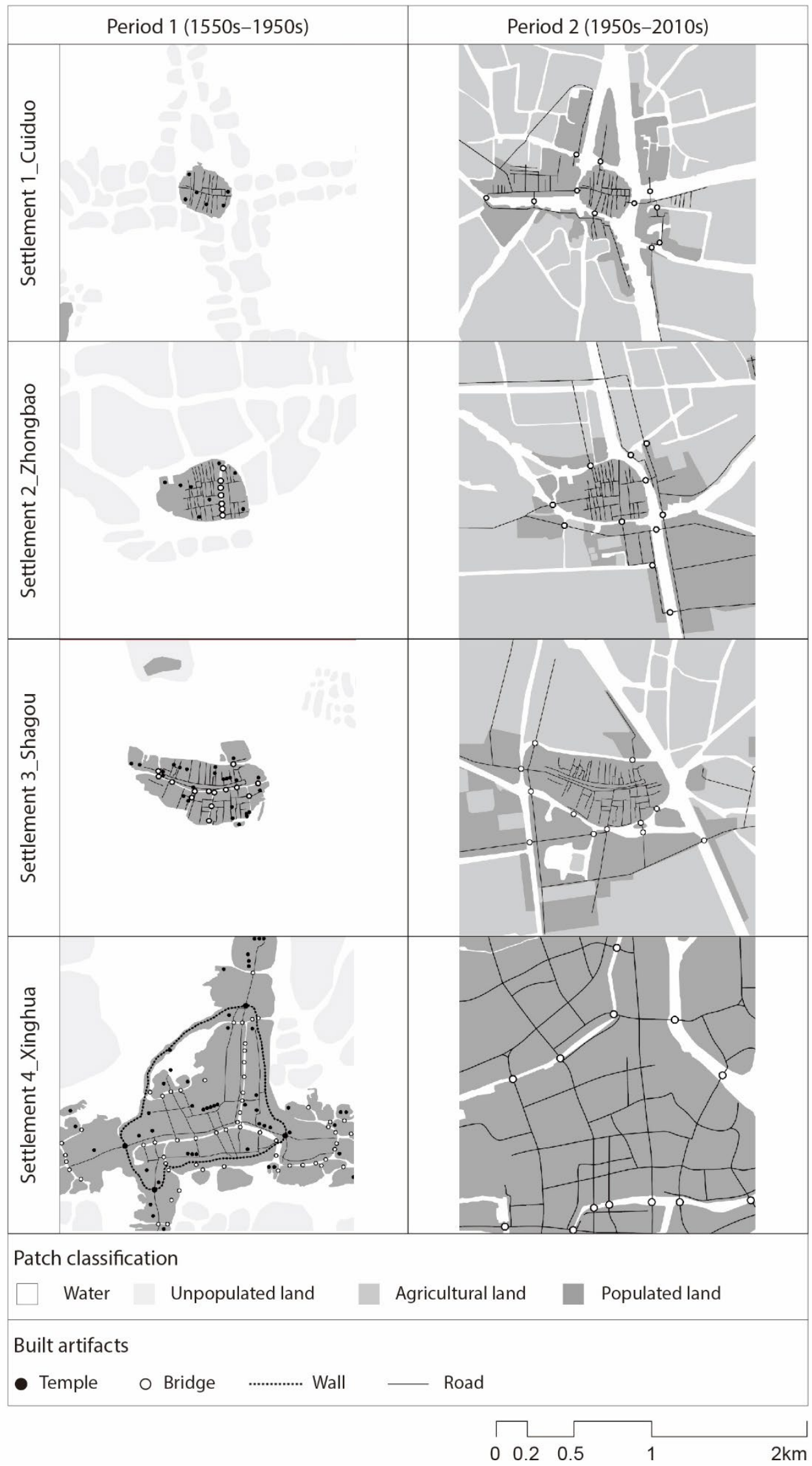

Figure 2. Islands in premodern waterscapes (Period 1) versus in modern dry development (Period 2). 


\section{Level 2: Island Corridor}

Island boundaries share similar information regarding structure and function in premodern times, but what are the drivers of different degrees of built behavior in this wet landscape? For example, Shagou grew from an individual island into five islands despite being isolated by water in all directions, and Xinghua was in fact a walled compound of land and water. We can examine boundary structure and function at the larger scale of the wet landscape to understand these morphological differences. Patch classification must be re-designated to achieve a more elaborate differentiation between water and land at this scale. On this level, lakes and reed marshes constitute wide boundaries and function as a versatile medium (Figure 3 , left). These bodies of water can both slow floodwater during periods of flooding and provide irrigation water in dry seasons. Reed marshes can also function as a three-dimensional barrier, protecting islands from intrusion. It is recorded that island settlements survived pirate attacks in the Ming dynasty (Matsuura, 1997) and were selected for military bases in the second Sino-Japanese war (1937-1945) and the Chinese Civil War (1945-1949).

These functional boundaries have a crucial impact on the emergence of island settlements and the thriving of island society. This can be directly verified by the history of the island settlements in the lowlands. Xinghua was first founded as a Hsien (county-level city in the agrarian society) as late as the $10^{\text {th }}$ Century $\mathrm{AD}$, which is unusual because other walled cities in Lixiahe were founded much earlier, before the $3^{\text {rd }}$ Century BC. For example, Yancheng (盐城), which was situated in a more vulnerable coastal area, was founded around 200 BC. Historians have argued that a Hsien was established in the lowlands in order to regulate the growing local population ( 丁 \& 汪, 1929). Cuiduo and Zhongbao appeared later and were founded by a group of forced immigrants from the south Yangtze River delta area in the $14^{\text {th }}$ Century. The same group of immigrants built most of the island settlements in the lowlands despite the lowlands being hit by severe natural disasters on an annual basis in this period.

Under these specific social and natural contexts, a water corridor system connecting island settlements emerged in the mid-19 $9^{\text {th }}$ Century (Figure 3, left). Isolated islands are connected through water trails in reed marshes or between paddy fields. The water corridor network, centered on Xinghua in a radiating pattern, is visually distinguished from the others due to its spatial continuity in the water-land environments. Between the mid- $16^{\text {th }}$ and $18^{\text {th }}$ Centuries, these lowlands became a traffic node supporting commodity exchanges within the Lixiahe region. Xinghua, the administrative center, served as a hub for collecting grain, which was a major source of state revenue. Some island settlements in this water corridor network had served as market towns for centuries. For example, Zhongbao is a market town on a latitudinal water corridor connecting the coastal salt fields and the eastern plains, while the market town of Shagou is on a longitudinal water corridor connecting the northern and southern plains.

Since the mid-20 $0^{\text {th }}$ Century, island relations based on the water corridor system have been altered. First, a new social order was established in the lowlands shortly after the start of the socialist era. In the years 1958-1983, island settlements were recombined into a three-tier socio system (O’Leary \& Watson, 1982) aimed at maximizing the spatio-economic benefits of agricultural production (兴化县地名录, 1983). As a result, socio-economic relations among island settlements were embedded into different spatial clusters for collective management. In the 1970s, tremendous efforts were made to construct waterways with the 
aim of improving the drainage capacity of this lowland watershed. Accordingly, the meandering natural waterways were straightened and widened, and some were replaced by navigable canals. Such adjustments in the water corridor system appear slight when considered on the regional level, but when seen at the level of the individual island, they meant that some island settlements were removed from their earlier island-to-island relations.

The integration of land transportation within Lixiahe since the 1970s accounts for the most decisive driver for the formation of new island relations (Figure 3, right). With intense road construction, the rhizomatic water corridor system has been replaced by an orthogonal land corridor system. Over the past decades, the maturing land corridor system has increased accessibility to each island settlement, but it has also weakened the significance of the boundary functions originating from the wet landscape, thereby detaching the development of island settlements from their earlier water-land environments. To support this argument, one can, for example, note the remarkable size differences of the built-up areas between the islands adjacent to and away from roads and the emergence of a large group of modern settlements in the southwest lowlands. These phenomena demonstrate the bottom-up breakage between social dynamics and the water-land environments.

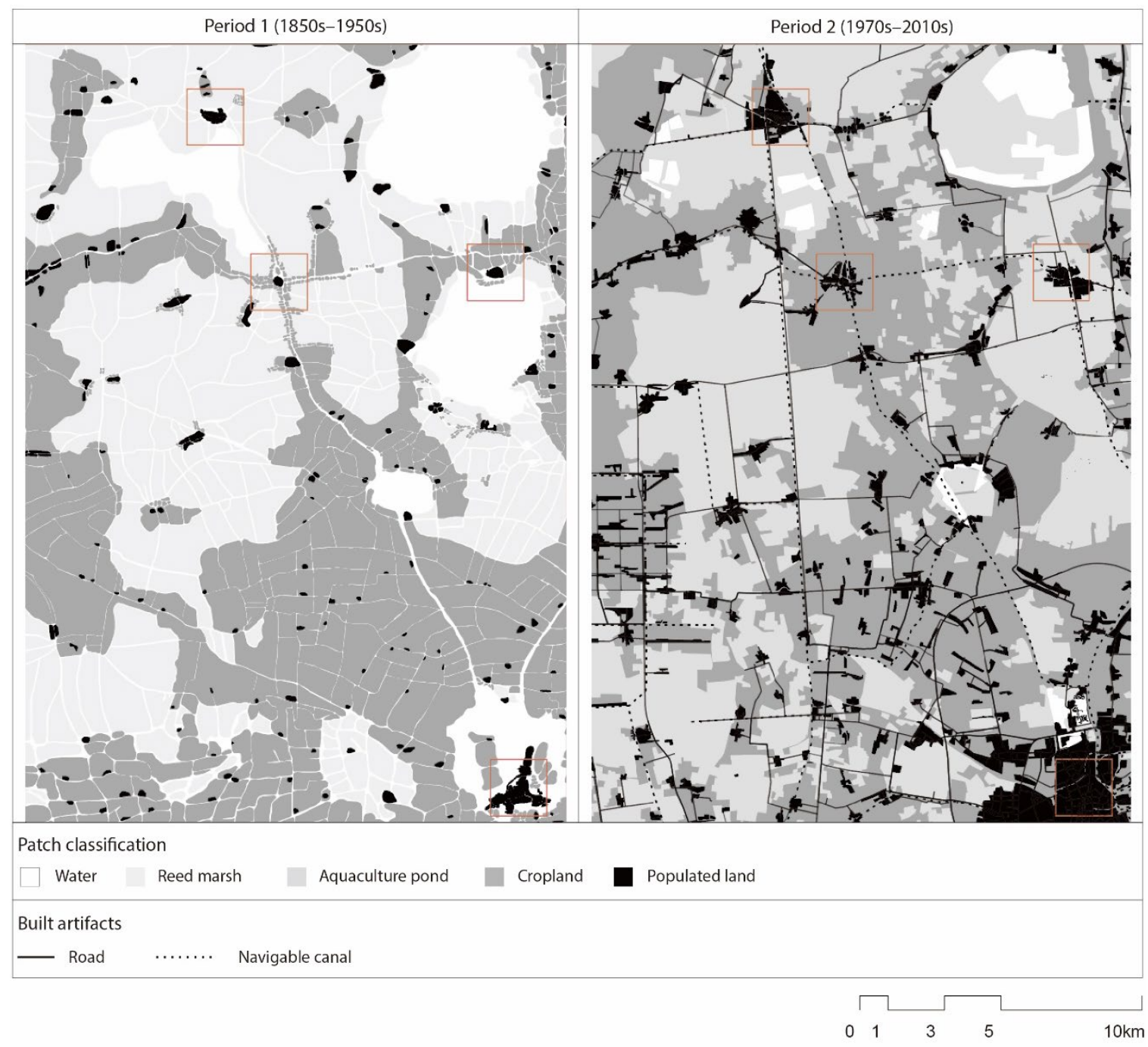

Figure 3. Island premodern water corridors (Period 1) versus modern land corridors (Period 2). 


\section{Level 3: Archipelago}

When we continue to step back and look at the lowlands using a coarser resolution, it is easy to identify the existence of an archipelago (Figure 4, left). Morphological information on this level indicates that the archipelago not only exists within natural waterscapes but is also attached to artificial waterscapes of paddy fields. Therefore, the archipelago is the third level to examine boundary structure and function, and consideration needs to be given to the socio-natural interactions taking place between the lowlands and the uplands. Here, 'lowlands' and 'uplands' are relative concepts, considering the bowl-shaped landform of Lixiahe. As the lowlands are at the bottom of the plain, the part of the plain with higher elevations can be defined as the uplands. Settlements in the uplands can also be regarded as islands but are situated in a somewhat drier landscape. The development of the upland island settlements follows a similar morphological logic to that of the lowland island settlements, but the degrees of human intervention in the water-land environment differ in the two areas.

In premodern times, Lixiahe's waterlogged paddy fields, which had been transformed from low-lying bodies of water, were the predominant spaces of agricultural cultivation. This agricultural mode is easily achieved by utilizing the microtopography of the lowlands (Yuan \& Wang, 2019) but is highly prone to flooding and droughts. In response to more frequent flooding in the $18^{\text {th }}$ Century, islanders in the uplands adopted an embankment system as a proactive response to environmental instability (吴, 1996). This system involves organizing living and farming activities within the same area and permits a controlled water-land nexus through the construction of layered embankments. Generally, the outer embankments are half a meter higher than the highest water level in the rainy season to prevent flooding, whereas the height of paddy fields is lower than the annual mean water level to achieve gravity irrigation in the dry season. In extreme conditions, islanders constructed temporary dams surrounding the living areas and transformed paddy fields into floodwater retention areas. In this system, the paddy fields are protected by embankments while the island community is protected by the paddy fields with embankments.

With long-term success in the uplands, this embankment system was introduced to the lowlands from the $18^{\text {th }}$ to the early $19^{\text {th }}$ Centuries (阮性传, 民国). Although the system is derived from systematic thinking, its construction process relies upon self-organization and is focused on the water-land nexus within the territory of an individual settlement, rather than within the wider Lixiahe region. The unorganized embankments destroyed the water corridor system and caused blockages in water channels due to increased subsidence, which eventually prevented water from flowing into and away from the lowlands. This built behavior on the individual island level intensified the extreme conditions of the water-land nexus in the lowlands: that is, there was frequently either no water or an excess of water. To increase their ability to control water flows, lowland islanders still resorted to the embankment method in the first half of the $20^{\text {th }}$ Century (Figure 4, left). This behavior further worsened the water shortages in the lowlands in the second half of the $20^{\text {th }}$ Century, which matches the time node when rivers were polluted and filled on the Level 1.

From the 1960s to the 1970s, under the impetus of the national strategy of "scientifically rational utilization of all available agricultural resources" (Chang, 1981), higher and longer embankments were built in Lixiahe to create more resilient paddy fields. At the same time, 
lakes and reed marshes in the lowlands were reclaimed as paddy fields from the late 1950s to the 1970s and then transformed into aquaculture ponds between the 1980s and 1990s (Wang et al, 2019). By the 2000s, Lixiahe's natural waterscapes were thoroughly transformed into artificial waterscapes with a stable water-land nexus. Within a short period, these drier conditions reduced consciousness of periodic natural disasters. New settlements began appearing, primarily located along the boundaries between the uplands and lowlands. As artificial waterscapes expand in the two areas, spatial heterogeneity between the lowlands and uplands diminishes, and it seems that the boundaries of the archipelago no longer exist (Figure 4, right).

As a matter of fact, the modern land corridor system has isolated island settlements from the Lixiahe ecosystem. In the early 1970s, highways were built in the uplands due to the prioritization of economic development. The construction of these land arteries prompted rapid industrialization of the uplands in the 1980s, leading to even wider highway network coverage within the uplands in the following decade. In the same period, however, there was only one interregional highway connecting the lowlands and uplands. To develop land transportation in the lowlands and ensure economic efficiency, island settlements were integrated into several land corridor networks belonging to different political administrations in the uplands. Access to lowland settlements was thus determined by their spatial proximity to upland settlements. As a result, lowland island settlements were positioned as the end nodes of transportation networks, becoming the remotest parts of the Lixiahe plains.

This sense of spatial remoteness has produced demographic changes, as younger islanders increasingly flee the lowlands and migrate to more urbanized, developed, and drier areas. The ancient lowlands society has become a socio-economic backwater of the Lixiahe region in modern times. Meanwhile, a series of environmental crises, including water quality problems and a return of issues connected with natural disasters, make life in the lowlands more challenging.

Over the past decade, there has been a river-lake-wetland restoration movement in the lowlands, driven by environmental performance evaluations and the rural revitalization movement. By decreasing illegal aquaculture ponds that were constructed before the 2000s and promoting ecological aquaculture methods, local governments have begun the process of eco-environmental restoration (刘 et al, 2015; Wang et al, 2019). Some island settlements have sought to recreate picturesque water villages by restoring the formerly covered rivers and providing riverine leisure activities, which are expected to promote the tourism economy (Figure 5). An identity assemblage is emerging in the lowlands: an isolated archipelago that serves same-day tourism as well as an aquapelago (Hayward, 2012) that supports daily socioeconomic life. 


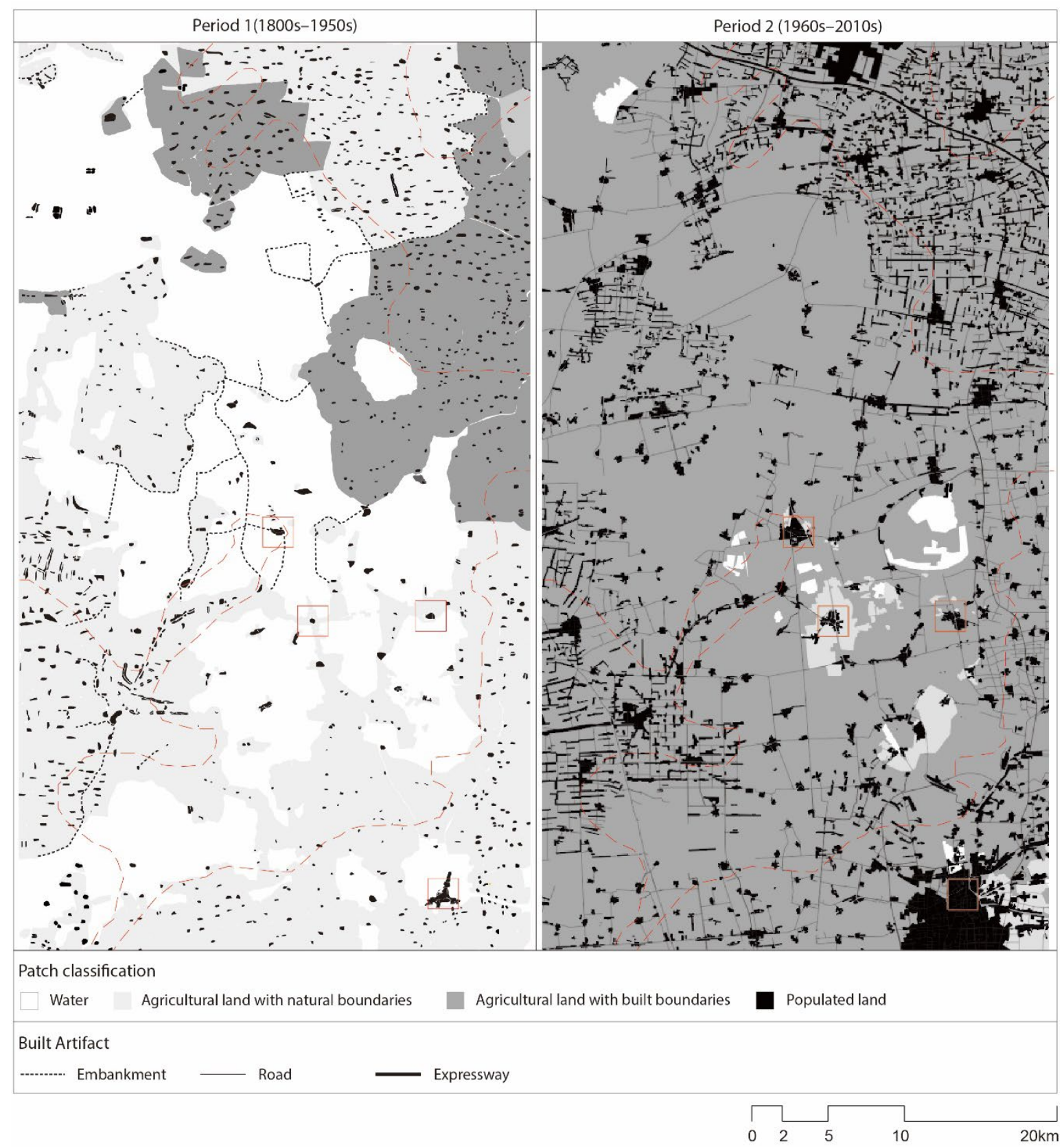

Figure 4. Environmental change from a premodern waterscape (Period 1) to a modern landscape (Period 2), with red dash lines marking the rough boundary between the lowlands and uplands. 

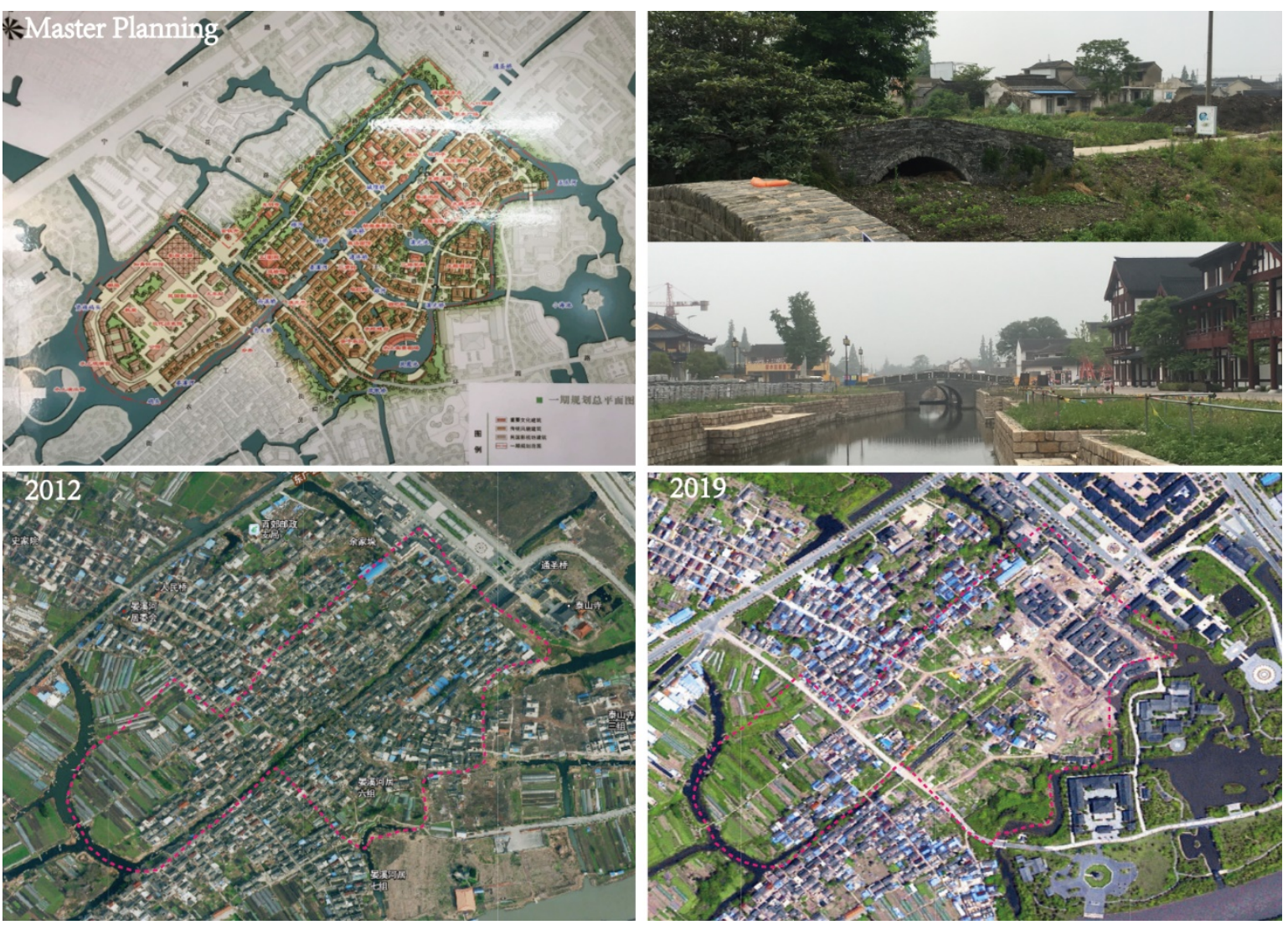

Figure 5. The island settlement of Xixi (西溪) under reconstruction driven by tourism development. The top-right two images show a previously paved-over river and a reconstructed riverine public place within this settlement. Below, two satellite maps illustrate the transformation of this settlement between 2012-2019 Satellite image source: http://jiangsu.tianditu.gov.cn/server/index

\section{Conclusion and discussion}

Tracing the interwoven socio-natural relationships in two periods on three levels reveals that Lixiahe's island societies and water-land environments constitute a complex socio-natural system (Van der Leeuw \& Aschan-Leygonie, 2005; Holling, 1973). Empirical knowledge of resilience generated from this model might provide historical lessons for places that are still undergoing dry development as part of modernization or urbanization processes in other wet landscapes (Grydehøj \& Casagrande, 2020; Pittock, 2019; Ashraf, 2014). In addition, the boundary approach is applicable to island studies on the relationship between social dynamics and natural environments.

To conclude, a diachronic observation provided three perspectives to link resilience in a socio-natural system and planning/architectural practice in wet landscapes.

1. The nested mechanism. Island settlements should be considered as part of this socionatural system rather than as spatially discrete entities. They cannot be completely separated from wet conditions despite the intensive dry development in modern times. As shown in the analysis of the modern period, an overwhelming dry development can trigger a series of crises. This socio-natural system needs to be further explored in "flow-structures" (Van der Leeuw \& Aschan-Leygonie, 2005) instead of statically hierarchical structures because one 
hidden driver of the evolution of the island society is the water-land nexus, which is essentially a flowing process in nature. The flow structures can be further unveiled by the nested relationships among three levels. Individual island settlements were conditioned by the environment of the lowlands. The socio-natural order generated by cooperation among island settlements (see Level 2, island corridor) can influence social dynamics on both the individual island and archipelago levels. For example, island settlements owe their morphological differentiations to their spatial relationships within the island corridor systems, while the emergence of the archipelago or aquapelago is a result of socio-economic dynamics facilitated by the island corridor systems. This nested mechanism may help explain why a variety of crises sprung up so quickly in the dry scenario of the modern period. If anything, modernity has enhanced this nested mechanism: dry development on every level can accelerate the pace of development and change within this socio-natural system.

2. The effects of built artifacts. Built artifacts work as a medium for revealing the waterland nexus and intervening in water-land environments. A tentative conclusion to the recent river-lake-wetland restoration movement is that there will be a substantial expansion of waterscape areas in the future in response to diverse 'dry' crises. This raises questions about how to alleviate the space use conflict between water-based ecological benefits and land-based economic development. One hypothesis is that built artifacts, such as infrastructure and public buildings, can work as agents to synergize aquatic and terrestrial flows (logistics, socio-cultural activities, etc.). Therefore, future construction projects should consider the socio-economic activities that can be synchronically fostered by water and land environments because the dynamic water-land nexus is an enduring characteristic of the lowlands. Another hypothesis could be that the effects of the built artifacts are conditioned by socio-natural interactions, which remain subject to the nested mechanism, and that such effects need to be evaluated from a long-term perspective. This means that enhancing resilience on one level through building artifacts might have an impact on resilience on another level in the future. For example, constructing embankments on Level 1 was initially a success; however, it led to the deterioration of the water corridor system on Level 2 and, in turn, induced more intensive embankment construction on Level 3, which eventually triggered even more severe droughts and flooding. This is also in accord with the findings of scientific studies that artificial adjustment within low-grade river networks impacts the function of the fluvial system (Gregory, 2006; Sear \& Newson, 2003). If the restoration movement succeeds in promoting the tourism economy, one could question whether the recreation of river channels and other bodies of water on the individual island level might trigger the same built behavior on other levels and cause environmental degradation. It could be possible and informative to forecast the consequences of this built behavior, considering that researchers have set out to monitor and evaluate the changed river networks within Lixiahe in modern dry development ( $\mathrm{Lv}$ et al, 2018; Zhou et al, 2018).

3. The twin phenomena. A comparative study of two time periods informs us that there are three kinds of twin phenomena that recur in the evolution of this island society. First, wet conditions alternate with dry conditions in the lowlands: there are "rhythms of wet and dry" (Krause, 2017) in this wet landscape. Despite the significant decline in natural disasters in modern times, moderate waterlogging occurred in the southern lowlands in 2006, and moderate drought was seen in the northern lowlands in 2019. Design interventions for environmental resilience thus need to be able to respond to both overly wet and dry 
conditions. Second, it should be acknowledged that environmental and social crises are the results of socio-natural interactions (Van der Leeuw \& Aschan-Leygonie, 2005). Natural and social dynamics are interrelated in the lowland context. This study has demonstrated that the natural settings of the lowlands still play a role in the modern socio-economic dynamics of this island society. But the recreation and maintenance of the physical form of an island or archipelago as part of tourism initiatives seems to be unsustainable as the relationship between natural environments and social dynamics is merely supported by the seasonal tourism economy. Third, bottom-up and top-down actions are interrelated; they can cause crises for one another when embedded within cultural preference. For example, massive land reclamation within individual settlements exacerbated the overall dry condition in the lowlands, and modern planning ignoring the socio-natural interactions led to the current trend of migration in island settlements.

Binary conceptions of wet/dry, natural/social, and bottom-up/top-down affect the consequences of human interventions in this wet landscape. Thinking about these twin phenomena might enhance design thinking in relation to resilience in socio-natural systems.

\section{Acknowledgements}

This study has benefited from discussions with Brian McGrath (Parsons School of Design). Comments and suggestions from Brian McGrath, David Grahame Shane (Columbia University), anonymous reviewers, the editors of Island Studies Journal, and Likai Wang (Nanjing University) are grateful acknowledged. I am also grateful for the financial support from the China Scholarship Council (No. 201806190192) and the Postgraduate Research \& Practice Innovation Program of Jiangsu Province, China (No. KYCX10_005).

\section{References in English}

Ambastha, K., Hussain, S. A., \& Badola, R. (2007). Resource dependence and attitudes of local people toward conservation of Kabartal wetland: A case study from the IndoGangetic plains. Wetlands Ecology and Management, 15(4), 287. https://doi.org/10.1007/s11273-006-9029-z

Ashraf, K. (2014). Water as Ground. In Mathur, A., \& Da Cunha, D. (Eds). Design in the terrain of water (pp. 83-97). Applied Research + Design Publishing.

Cadenasso, M. L., \& Pickett, S. T. A. (2007). Boundaries as structural and functional entities in landscapes: Understanding flows in ecology and urban design. In Designing Patch Dynamics. New York: GSAPP, Columbia University.

Cadenasso, M. L., Pickett, S. T., Weathers, K. C., \& Jones, C. G. (2003). A framework for a theory of ecological boundaries. BioScience, 53(8), 750-758. https://doi.org/10.1641/0006-3568(2003)053[0750:affato]2.0.co;2

Chang, S. D. (1981). Modernization and China's urban development. Annals of the Association of American Geographers, 71(2), 202-219.

Chang, S. D. (1970). Some observations on the morphology of Chinese walled cities. Annals of the Association of American Geographers, 60(1), 63-91. https://doi.org/10.1111/j.1467_ 8306.1970.tb00704.x 
Chen, X. (1998). Changjiang (Yangtze) River Delta, China. Journal of Coastal Research, 14(3), 839-858.

Dar, S. A., Bhat, S. U., Rashid, I., \& Dar, S. A. (2020). Current status of wetlands in Srinagar City: threats, management strategies, and future perspectives. Frontiers in Environmental Science, 7, 199. https://doi.org/10.3389/fenvs.2019.00199

Giblett, R. (2016). Cities and wetlands: the return of the repressed in nature and culture. Bloomsbury. Gregory, K. J. (2006). The human role in changing river channels. Geomorphology, 79(3-4), 172-191. https://doi.org/10.1016/j.geomorph.2006.06.018

Grydehøj, A. (2015). Island city formation and urban island studies. Area, 47(4), 429-435. https://doi.org/10.1111/area.12207

Grydehøj, A., \& Casagrande, M. (2020). Islands of connectivity: Archipelago relationality and transport infrastructure in Venice Lagoon. Area, 52(1), 56-64. https://doi.org/10.1111/area.12529

Grydehøj, A., Pinya, X. B., Cooke, G., Doratlı, N., Elewa, A., Kelman, I., \& Swaminathan, R. (2015). Returning from the horizon: introducing urban island studies. Urban Island Studies, 1, 1-19. https://doi.org/10.20958/uis.2015.1

Guan, Y., Bai, J., Tian, X., Zhi, L., \& Yu, Z. (2021). Integrating ecological and socioeconomic systems by carbon metabolism in a typical wetland city of China. Journal of Cleaner Production, 279, 123342. https://doi.org/10.1016/j.jclepro.2020.123342

Ha, C., Zhu, J., Ye, N., Huang, J., Gong, J., \& Lu, H. (2005). Formation and evolution of a forgotten Delta -- the Huaihe River delta, eastern China. Geological Bulletin of China, 24(12), 1094-1106.

Hayward, P. (2012). Aquapelagos and aquapelagic assemblages. Shima, 6(1), 1-10.

Holling, C. S. (1973). Resilience and stability of ecological systems. Annual Review of Ecology and Systematics, 4(1), 1-23.

Jin, Q. (1988). The history and current trends of research on rural settlement geography in China. Acta Geographica Sinica, 55(4), 311-317. (in Chinese with English abstract)

Krause, F. (2017). Rhythms of wet and dry: Temporalising the land-water nexus. Geoforum. https://doi.org/10.1016/j.geoforum.2017.12.001

Lafaye de Micheaux, F., Mukherjee, J., \& Kull, C. A. (2018). When hydrosociality encounters sediments: Transformed lives and livelihoods in the lower basin of the Ganges River. Environment and Planning E: Nature and Space, 1(4), 641-663. https://doi.org/10.1177/2514848618813768

Lahiri-Dut, K. (2014a). Beyond the water-land binary in geography: Water/lands of Bengal re-visioning hybridity Kuntala Lahiri-Dut. ACME: An International Journal for Critical Geographies, 13(3), 505-529.

Lahiri-Dutt, L. (2014b). Chars islands that float within rivers. Shima: The International Journal of Research into Island Cultures, 8(2), 22-38.

Liu, J., Zang, C., Tian, S., Liu, J., Yang, H., Jia, S., You, L., Liu, B., \& Zhang, M. (2013). Water conservancy projects in China: Achievements, challenges and way forward. Global Environmental Change, 23(3), 633-643.

https://doi.org/10.1016/j.gloenvcha.2013.02.002 


\section{Dongxue Lei}

Lv, H., Zhou, F., Li, N., \& Xu, Y. (2018). Evolution Characteristics of the River Network in the Typical Area of Lixiahe Region. Resources and Environment in the Yangtze Basin, 27(2), 380-385. (in Chinese with English abstract)

Matsuura, A. (1997). The Chinese Pirates During the Ming and Qing Dynasty [J]. Studies In Qing History, 1. (in Chinese with English abstract)

McGrath, B., Marshall, V., Cadenasso, M.L., Grove, J.M., Pickett, S.T.A., \& Towers, J. (Eds). (2007). Designing Patch Dynamics. Columbia University Graduate School of Architecture, Preservation and Planning.

McGrath, B., \& Lei, D. (2021). The embodied resilience of architecture and built form. In Ungar, M. (Eds). Multisystemic resilience: Adaptation and transformation in contexts of change. Oxford University Press. https://doi.org/10.1093/oso/9780190095888.003.0032

Mitsch, W. J., \& Gosselink, J. G. (2000). The value of wetlands: importance of scale and landscape setting. Ecological Economics, 35(1), 25-33. https://doi.org/10.1016/s0921-8009(00)00165-8

Mitsch, W. J., \& Gosselink, J. G. (2011). Wetlands. John Wiley \& Sons.

O'Leary, G., \& Watson, A. (1982). The role of the People's Commune in rural development in China. Pacific Affairs, 55(4), 593-612. https://doi.org/10.2307/2756843

Pinke, Z., Ferenczi, L., Gábris, G., \& Nagy, B. (2016). Settlement patterns as indicators of water level rising? Case study on the wetlands of the Great Hungarian Plain. Quaternary International, 415, 204-215. https://doi.org/10.1016/j.quaint.2015.11.032

Pugh, J. (2013). Island movements: thinking with the archipelago. Island Studies Journal, 8(1), 9-24.

Pugh, J. (2018). Relationality and island studies in the Anthropocene. Island Studies Journal, 13(2), 93-110. https://doi.org/10.24043/isj.48

Pittock, J., \& Connell, D. (2019). Dikes, rice, and fish: how rapid changes in land use and hydrology have transformed agriculture and subsistence living in the Mekong Delta. Regional Environmental Change, 19(7), 2069-2077. https://doi.org/10.1007/s10113-019-01548-x

Robertson, H. A., \& McGee, T. K. (2003). Applying local knowledge: the contribution of oral history to wetland rehabilitation at Kanyapella Basin, Australia. Journal of environmental management, 69(3), 275-287. https://doi.org/10.1016/s0301-4797(03)00155-5

Sear, D. A., \& Newson, M. D. (2003). Environmental change in river channels: a neglected element. Towards geomorphological typologies, standards and monitoring. Science of the Total Environment, 310(1-3), 17-23. https://doi.org/10.1016/s0048-9697(02)00619-8

Stratford, E., Baldacchino, G., McMahon, E., Farbotko, C., \& Harwood, A. (2011). Envisioning the archipelago. Island Studies Journal, 6(2), 113-130.

Tockner, K., \& Stanford, J. A. (2002). Riverine flood plains: present state and future trends. Environmental Conservation, 308 330. https://doi.org/10.1017/s037689290200022x

Ummai, H., Fouzia, H., Asif, I., Mallik Sezan, M., \& Arif, M. (2011). Remote sensing \& GIS based spatio-temporal change analysis of Wetland in Dhaka City, Bangladesh. Journal of Water Resource and Protection, 3(11). https://doi.org/10.4236/jwarp.2011.311088

Van der Leeuw, S. E., \& Aschan-Leygonie, C. (2005). A long-term perspective on resilience in socio-natural systems. Micro-Meso-Macro: Addressing Complex Systems Couplings, London, World Scientific, 227-264. https://doi.org/10.1142/97898127014040013 
Wilkinson, C. (2012). Social-ecological resilience and planning: an interdisciplinary exploration. Doctoral dissertation, Department of Systems Ecology, Stockholm University.

Wang, Y., Wang, D., Qian, J., Gao, S., Wang, C. (2019). Study on planning and benefit analysis of returning polder area to lakes in plain water network area - a case study of Lixiahe Lake areas in Xinghua County. Jiangsu Water Resources, 5, 16-24. (in Chinese with English abstract)

Xu, P. (1995). Impact of future sea level rise on flood and water logging disasters in lixiahe region. Chinese Geographical Science, 6(1), 35-48. https://doi.org/10.1007/s11769-996$\underline{0034-1}$

Ye, Q. (1986). On the development of the abandoned yellow river delta in northern Jiangsu province. Acta Geographica Sinica, 41(2), 112-122. (in Chinese with English abstract)

Yuan, H., \& Wang, J. (2019). Development of the pattern of Weitian and Duotian in Xinghua Region. Samson, 38(2), 133-144. (in Chinese with English abstract)

Zhang, Y., Chen, S., \& Gu, G. (2016). Spatiotemporal patterns of tidal disasters in the north jiangsu plain during historical periods. Marine Science Bulletin, 35(1), 30-37. (in Chinese with English abstract)

Zhou, F., Huihua, L., \& Liu, C. (2018). Change of river system in the Lixiahe region during urbanization. South-to-North Water Transfers and Water Science \& Technology, 16(1), 144150. (in Chinese with English abstract)

\section{References in Chinese}

刘, 锦霞., 陈, 栋., 朱, 大伟., \& 冯, 婧. (2015). 里下河地区湖泊湖荡恢复模式设想与实

践. 湖泊湿地与绿色发展一中国湖泊论坛.

阮, 性传. (民国). 兴化县小通志校注.

吴, 必虎. (1996). 历史时期苏北平原地理系统研究. 上海: 华东师范大学出版社.

兴化县地名委员会. (1983). 江苏省兴化县地名录.

兴化市防汛防旱指挥部办公室. (2001). 兴化防汛防旱手册.

丁, 文江., 汪, 胡桢. (1929). 扬子江下游之地质(续). 扬子江水道整理委员会月刊, 1(3): $1-30$. 